\title{
Stress experienced by women after premature labor is conditioned by their personality
}

\author{
Aneta Libera, Bożena Leszczyńska-Gorzelak, Jan Oleszczuk \\ Department of Obstetrics and Perinatology, Medical University of Lublin, Poland
}

\begin{abstract}
Objectives: The aim of the study was to analyze a possible correlation between personality traits and the level of stress experienced by women after premature labor.

Material and methods: The analysis was carried out on the basis of a study conducted in 96 women after premature labor. The following tools were used: Personality Inventory NEO-FFI, Parental Stressor Scale: NICU (SSR:OITN), and personal data questionnaire. It was an exploratory study since the SSR:OITN method is only applied to find out the characteristic features of stress induced by prematurity, and, therefore, it cannot be applied to study the control sample (i.e. women who delivered at term).

Results: The obtained results revealed significant correlations between the level and structure of stress connected with premature labor and personality traits. The general level of stress and all its components (infant's clinical characteristics and medical procedures, personal and interpersonal problems as well as parental competence) correlated positively with Neuroticism. Negative correlations between the general level of stress together with its parental competence factor and Extraversion and Openness to experience were found. Agreeableness correlated negatively with parental competence stress. No correlation between the level of stress and Conscientiousness was observed.

Conclusions: Our findings shed new light on how women after premature labor experience stress, and suggested an effective medical-psychological-therapeutic support aiming at reducing the level of trauma. The SSR:OITN Scale is proposed as one of the basic methods used to diagnose difficulties experienced by the investigated women.
\end{abstract}

Key words: premature labor, personality, parental stress

\section{INTRODUCTION}

Reproductive psychology and medicine resources indicate that premature labor tends to be a traumatic experience for a woman. Experiencing such a stressful situation may be the cause of long-term psychological and emotional disorders. Also, it can negatively affect a woman's self-perception, her relationship with the child (and, consequently, the psychosomatic development of the child), and the family itself [1-8].

Veddovi et al. [9], stated that premature labor itself does not constitute a direct cause of depression, yet trauma experienced by a woman after premature labor may significantly increase the risk of depressive disorders. According to current research, women after premature labor reveal more depressive symptoms in the first days after childbirth [10], as well as 1 month after delivery [11], and after a longer period of time, e.g. after 14 months [12], as compared to mothers who delivered at term. Moreover, mothers of children born prematurely experience symptoms typical for posttraumatic stress disorder (PTSD), such as obsessive thoughts, panic attacks, avoidance (e.g. of the place connected with trauma, relationship with the child), sense of emotional torpor, reoccurring flashbacks, nightmares, or hyperactivity. Trauma experienced by women after premature labor may affect the cognitive, emotional, motivational, and somatic spheres and its effects may be noticeable for a relatively long period of time, i.e. 6-18 months [12-14].

The manner in which stress is experienced correlates with a number of factors, including personality. Experts claim that personality traits are among the most powerful 
predictors of stress vulnerability. One of the most popular contemporary personality concepts is the five factor model by P.T. Costa and R.R. McCrae. According to these authors, personality can be categorized with regard to traits such as Neuroticism, Extraversion, Agreeableness, Openness to experience, and Conscientiousness [15, 16]. Among the above-mentioned factors, Neuroticism and Extraversion seem to be of greatest significance as far as the experience of stress is concerned. Neuroticism determines the vulnerability to negative emotions and it is correlated with low self-esteem, tendency to experience anxiety, hostility, anger, worrying, despondency, depression, and pessimistic approach to life. Extraversion tends to be associated with experiencing positive emotions and wellbeing and, therefore, is perceived as a trait protecting from stress. Openness to experience, Agreeableness and Conscientiousness should also be considered when analyzing the vulnerability to stress, yet they are not as significant as Neuroticism and Extraversion. Individuals who are open to experience tend to be more creative, have tolerance for new unknown situations, and are willing to discover them. High level of Agreeableness usually translates into more social interactions and higher probability of obtaining social support, whereas Conscientiousness is correlated with prudence, meticulousness and persistence, which proves to be helpful when applying active and efficient stress management techniques.

The risk of postpartum psychiatric disorders is correlated with a number of factors, including personality. According to current research, high level of Neuroticism tends to be the most powerful predictor of postpartum depression or postpartum psychosis, progressing to bipolar or schizoaffective disorders [17]. Additionally, low levels of Extraversion, Openness to experience, Agreeableness, and Conscientiousness may increase the risk of postpartum psychiatric disorders. Patients with higher level of Neuroticism are more vulnerable to postpartum depression or bipolar disorders [4-6]. According to Holditch-Davis et. al [4], there are correlations between scores obtained by women after labor on the Edinburgh Postnatal Depression Scale (EPDS), in the Mood Disorders Questionnaire (MDQ), Neuroticism (positive correlations), Agreeableness and Conscientiousness (negative correlations).

Stress experienced due to premature labor is of a special type since it is connected with the situation when the health and life of an infant is threatened [14, 18-20]. This kind of stress experienced by the parents is related to many factors, such as:

- life-threatening situation for the infant and high risk of developmental disorders;

- hospitalization of the infant in the neonatal intensive care unit, associated with a number of intensive medical treatments, which results in limited contact with the child;

- unexpected interruption of the psychological processes preparing a woman for becoming a mother, which can influence postpartum adaptation as well as early mother-child bonding;

- experiencing many, at times contradictory, emotions, e.g. fear for the infant's life and its potential disability, helplessness, sense of losing control, feelings of guilt and injustice, anger, sadness, hope, and feeling of loss.

Studies on this particular type of stress have focused not only on discovering and understanding the mechanisms responsible for the fact that some women cope with the situation of premature labor worse than others $[4,7$, 21-23], but also on discovering appropriate research tools that would allow for precise measurement of quantitative and qualitative stress [24-27]. The findings confirmed the diversification of the structure of stress experienced by the parents in the situation of premature labor. M.S. Miles was among the first in the USA to try to deal with this problematic area [24]. Her research resulted in creating the Parental Stressor Scale: Neonatal Intensive Care Unit (PSS:NICU) scale based on the model identifying 3 main factors that constitute the source of potential stress in the parents of the hospitalized infant, i.e. infant's behavior and appearance, alternation of the parental role resulting from the child's illness and hospitalization, as well as the sights and sounds of the hospital unit. In the UK, T. Reid continued the research initiated by M.S. Miles [25, 26]. She updated and adjusted the above-mentioned scale to the British population using the name Neonatal Unit Parental Stress Scale (NUPS). The Polish equivalent, used to measure the level and structure of stress experienced by women after premature labor and characterized by strong psychometric properties, is called the Parental Stressor Scale: Neonatal Intensive Care Unit (SSR:OITN) [27]. The analysis of the findings obtained with the use of SSR:OITN revealed the presence of three factors that can be identified in the structure of stress connected with premature birth: infant's clinical characteristics and medical procedures (Factor I), personal and interpersonal problems (Factor II), and parental competence (Factor III). Stress related to Factor I is greatly connected with infant's treatment and is accompanied by the feeling of having no influence on the infant's condition (and simultaneously, a strong need to do something to help him/her), sense of no control, negative feelings about the medical procedures, mainly based on the sense of sight (seeing needles, advanced medical equipment, sudden alarms, infant's fragile appearance and small size). Factor II encompasses stress experienced in relation to the following: difficulties in the relationship with the partner, family, and friends, a sense of 
lack of time, difficulties with managing the patient-parental duties, difficulties and concerns after one's own and infant's hospitalization connected with establishing regular life patterns, and discomfort caused by the absence of a private space in relationship with the child. Factor III relates to stress connected with negative feelings about the parent-infant relationship, negative feelings about closeness of medical staff to the child, a sense of separation as well as lack of parental competence [27].

Notably, the structure of stress experienced after premature labor by Polish and British women differs, owing to cultural discrepancies, different organization of health care and socioeconomic status of the respondents [24-27]. As an example, some items with the same content constitute different factors in both tests, e.g. some items forming the KM factor in the NUPS constitute a part of the SKD factor in the SSR scale. For example: 'feeling helpless and unable to protect my baby from pain and painful procedures';'feeling helpless about how to help my baby during this time;';not being able to take care of my baby myself'; 'not being able to hold my baby when I want'; 'being separated from my baby'.The fact that the above-mentioned items are included in the SKD and PM factors may indicate that mothers from the Polish population focus mainly on the treatment process and, therefore, the sphere of their intimate mother-child relationship remains relatively neglected.

\section{OBJECTIVES}

Our study was of exploratory nature, which means it was directed at investigating and discovering the characteristic features of a given phenomenon. In our case, the investigated variable is the quantitative and qualitative aspect of stress induced by prematurity. This variable is treated as a dependent one which, according to the literature $[15,16]$, is significantly influenced by other relatively constant factors such as personality traits. It is impossible to create a research model which would include a control sample and which would compare differences between experiencing stress by the studied sample (mothers of premature babies) and the control sample (women who delivered at term) since the SSR:OITN method is only applied to find out the characteristic features of stress induced by prematurity (it investigates only the factors present in a situation of premature labor), and, therefore, it cannot be applied to the control sample. Hence, a research hypothesis has not been formulated.

\section{MATERIAL AND METHODS}

The study included 96 women after premature labor (gestational age $<37$ weeks, birth weight $<2500$ g), hospitalized at the Department of Obstetrics and Perinatology, Medical University of Lublin, whose newborn infants required hospitalization in the Neonatal Intensive Care Unit.
Table 1. The structure of the studied sample with regard to age

\begin{tabular}{|l|c|c|c|c|c|}
\hline Variable & N & Min. & Max. & M & SD \\
\hline Age & 96 & 17.00 & 42.00 & 29.52 & 5.39 \\
\hline
\end{tabular}

Table 2. Sociodemographic structure of the studied sample

\begin{tabular}{|c|c|c|c|}
\hline \multicolumn{2}{|l|}{ Variable } & $\mathbf{N}$ & $\%$ \\
\hline \multirow{4}{*}{ Education } & Higher education & 46 & 47.9 \\
\hline & Secondary education & 27 & 28.1 \\
\hline & Vocational school & 19 & 19.8 \\
\hline & Primary education & 4 & 4.2 \\
\hline \multirow{2}{*}{ Place of residence } & Urban & 53 & 55.2 \\
\hline & Rural & 43 & 44.8 \\
\hline \multirow{2}{*}{ Marital status } & Married & 87 & 90.6 \\
\hline & Single & 9 & 9.4 \\
\hline \multirow{2}{*}{ Partnership } & Yes & 95 & 99.0 \\
\hline & No & 1 & 1.0 \\
\hline \multirow{2}{*}{ Other children } & Yes & 35 & 36.5 \\
\hline & No & 61 & 63.5 \\
\hline \multirow{2}{*}{ Work activity } & Working & 63 & 65.6 \\
\hline & Not working & 33 & 34.4 \\
\hline \multirow{4}{*}{ Financial situation } & Very good & 13 & 13.5 \\
\hline & Good & 58 & 60.4 \\
\hline & Average & 24 & 25.0 \\
\hline & Bad & 1 & 1.0 \\
\hline
\end{tabular}

The structure of the studied sample with regard to sociodemographic and demographic variables is presented in Tables 1 and 2. The structure of the studied sample with regard to medical variables is presented in Tables 3 and 4.

Every respondent was informed of the aim, subject and course of the research and guaranteed anonymity. The participants completed the following questionnaire forms:

1. Personality Inventory NEO-FFI by P.T. Costa and R.R. McCrea (adapted to Polish realities by B. Zawadzki, J. Strelau, P. Szczepaniak and M. Śliwińska) measuring five basic personality traits: Neuroticism, Extraversion, Agreeableness, Conscientiousness, and Openness to experience [28].

2. Parental Stressor Scale: Neonatal Intensive Care Unit (Skala Stresu Rodziców: Oddział Intensywnej Terapii Noworodka, SSR:OITN) measuring the level and structure of stress experienced by parents of premature infants in NICU premises. The stress structure encompasses three factors - I. infant's clinical characteristics and medical procedures, II. personal and interpersonal problems, III. parental competence [27].

3. Patient data collection sheet - a method of collecting sociodemographic data about the respondents, 
Table 3. The structure of the studied sample presented as medical variables: gestational age at delivery, birthweight

\begin{tabular}{|l|c|c|c|c|c|}
\hline Variable & N & Min. & Max. & M & SD \\
\hline $\begin{array}{l}\text { Gestational } \\
\text { weeks at delivery }\end{array}$ & 95 & 25 & 34 & 31.47 & 2.72 \\
\hline Birth weight & 96 & 580 & 2500 & 1727.41 & 571.96 \\
\hline
\end{tabular}

Table 4. The structure of the studied sample presented as medical variables: parity, mode of delivery, number of children, anticipated risk of premature labor, planning for pregnancy

\begin{tabular}{|l|l|l|l|}
\hline Variable & First pregnancy & 51 & 53.1 \\
\hline \multirow{3}{*}{ Parity } & Next pregnancy & 45 & 46.9 \\
\hline \multirow{2}{*}{ Mode of delivery } & Vaginal birth & 21 & 21.9 \\
\cline { 2 - 4 } & Cesarean section & 75 & 78.1 \\
\hline \multirow{2}{*}{ Number of children } & One child & 77 & 80.2 \\
\cline { 2 - 4 } & Two children & 19 & 19.8 \\
\hline \multirow{2}{*}{ Miscarriages } & No & 73 & 76.0 \\
\hline \multirow{2}{*}{$\begin{array}{l}\text { Anticipated risk of } \\
\text { premature labor }\end{array}$} & Yes & 23 & 24.0 \\
\hline Yes & 52 & 54.2 \\
\hline Planning for & Planned pregnancy & 28 & 45.8 \\
\hline pregnancy & Unplanned pregnancy & 68 & 70.8 \\
\hline
\end{tabular}

as well as health and medical information concerning premature labor.

Pearson correlation coefficient $r$ was used to compare the obtained numerical data.

\section{RESULTS}

Statistical analysis of the obtained results was carried out with the use of the above-mentioned methods.

\section{Personality factors}

The NEO-FFI questionnaire was used to measure personality traits. Table 5 presents mean values as well as deviations of the results.

Taking into consideration standard deviations, it seems safe to conclude that the obtained personality portrait of

Table 5. Minimum, maximum and mean values as well as standard deviations of every NEO-FFI factor

\begin{tabular}{|l|c|c|c|c|}
\hline Personality traits & Min. & Max. & M & SD \\
\hline NEU & 3 & 41 & 24.82 & 7.23 \\
\hline EXT & 9 & 42 & 27.80 & 6.84 \\
\hline OPE & 13 & 40 & 24.61 & 5.12 \\
\hline AGR & 18 & 40 & 30.05 & 5.09 \\
\hline CON & 16 & 48 & 33.92 & 5.57 \\
\hline
\end{tabular}

Table 6. Minimum, maximum and mean values as well as standard deviations of every subscale and of the SSR:OITN general result

\begin{tabular}{|l|c|c|c|c|}
\hline $\begin{array}{l}\text { Factor I- clinical } \\
\text { characteristics and medical } \\
\text { procedures of the infant }\end{array}$ & 15 & 112 & 78.29 & 21.18 \\
\hline $\begin{array}{l}\text { Factor II - personal and } \\
\text { interpersonal problems }\end{array}$ & 0 & 93 & 37.92 & 24.15 \\
\hline $\begin{array}{l}\text { Factor III - parental } \\
\text { competence }\end{array}$ & 0 & 65 & 24.05 & 14.33 \\
\hline SSR:OITN SUM & 15 & 270 & 140.27 & 50.02 \\
\hline
\end{tabular}

women after premature labor is similar to a typical personality portrait of a normalized sample.

\section{Level and structure of stress}

Parental Stressor Scale: OITN was used to measure the level of stress. Table 6 shows mean results and their standard deviations obtained for each factor and the whole scale.

Mean general result obtained for the studied sample of women was 140.27. In terms of the studied factors of SSR:OITN, the highest score was obtained for Factor I, i.e. infant's clinical characteristics and medical procedures. Much lower mean results were noted for Factor II: personal and interpersonal problems and the lowest ones were obtained for Factor III: parental competence.

\section{Personality traits and stress level after premature labor}

The aim of the further investigation was to determine the existence of any correlation between the level of stress experienced by women after premature labor and their personality traits. The obtained results are presented in Table 7.

Significant correlations were observed between the level of stress experienced after premature labor and personality traits in the studied sample of women. The general level of stress, together with all of its components (stress tension experienced in terms of infant's clinical characteristics and medical procedures, personal and interpersonal problems as well as parental competence) correlated positively with Neuroticism. Negative correlations between the general level of stress, together with its parental competence factor, and Extraversion and Openness to experience traits, were also found. Agreeableness correlated negatively only with stress related to parental competence. No correlation between the level of stress and Conscientiousness was observed.

\section{DISCUSSION}

Our clinical experience with patients after premature labor demonstrates that every threat to the infant's life (or health) remains a source of powerful stress for the mother. 
Table 7. Pearson correlation coefficient $r$ between the results obtained on the SSR:OITN scale and on Personality Inventory NEO-FFI scale

\begin{tabular}{|l|c|c|c|c|c|}
\hline \multirow{2}{*}{ SSR:OITN } & \multicolumn{3}{|c|}{ NEO - FFI } & CON \\
\cline { 2 - 6 } & NEU & EXT & OPE & AGR & 0.08 \\
\hline $\begin{array}{l}\text { Factor I - clinical characteristics and medical } \\
\text { procedures of the infant }\end{array}$ & $0.0^{*}$ & -0.13 & -0.18 & -0.07 & -0.13 \\
\hline Factor II - personal and interpersonal problems & $0.35^{* *}$ & -0.15 & -0.13 & -0.16 & -0.18 \\
\hline Factor III - parental competence & $0.35^{* * *}$ & $-0.25^{*}$ & $-0.24^{*}$ & $-0.22^{*}$ & -0.08 \\
\hline SSR:OITN SUM & $0.35^{* *}$ & $-0.20^{*}$ & $-0.21^{*}$ & -0.17 & \\
\hline PSO.05* PSO.01*
\end{tabular}

$p \leq 0.05 ; *$ * $\leq 0.01 ;{ }^{* *} p \leq 0.001$

However, there are some differences concerning the subjective evaluation of the meaning the prematurity carries for a woman. Despite an objective threat to the child's life or health, some patients reveal signs of stress only to a minor extent, or not at all, whereas others, whose situation is much less complicated, have significant difficulties with emotional (anxiety, tension, low mood, feeling of guilt, sadness, grief, weepiness, helplessness), physical (fast-paced heartbeat, quickened breath, tight throat, excessive sweating, tight stomach), and psychosocial functioning (becoming withdrawn, showing a tendency to shut oneself off from the world vs. looking for social contacts). The above-listed observations have led us to explore the problem and analyze the quality (characteristics) of stress caused by prematurity, as well as to search for factors determining the way mothers experience it. The starting point was the assumption that personality is considered as one of the most powerful predictors of stress vulnerability $[15,16]$. Our analysis confirmed the existence of significant correlations between personality traits and stress level experienced by women faced with prematurity. However, there are some discrepancies among correlations between various personality traits and chosen stress aspects. Neuroticism seems to be the most important as far as stress induced by prematurity is concerned. Highly neurotic people apply less constructive stress management techniques, i.e.: avoidance, denial, difficulties in making decisions, dreaming, self-blame $[15,16,28-30]$. With reference to the sample of the investigated women, it may be assumed that higher level of Neuroticism corresponds to a greater tendency for experiencing stress, with the strongest correlations concerning parental competence (Factor III SSR:OITN) and personal and interpersonal problems (Factor II SSR:OITN). Mothers with higher level of Neuroticism tend to experience difficult emotions coming into contact with a child (sadness, grief, anxiety, tension, helplessness, feeling of guilt) and negative assessment of their own skills concerning the role of a mother (e.g. lack of competence and/or learning how to be a good mother), which can result in experiencing difficulties/resistance when bonding with the child. These mothers find it more difficult to organize their own time during hospitalization, have concerns about establishing regular life patterns after being discharged, and more often experience negative feelings in relations with the family and the friends (e.g. anxiety about emotional reactions of the family, sense of lack of understanding and loneliness).

Neuroticism is also determined by the level of stress connected with the infant's clinical characteristics and medical procedures (Factor I SSR:OITN). Patients with higher level of this trait may experience negative emotions concerning the child's appearance (e.g. its fragility and small size, unfamiliar skin color, unnatural breathing), its condition (the pain and sadness it experiences, its weakness, its sudden movements stand for discomfort), and medical procedures (being connected to the medical equipment, seeing needles and tubes, IVs, intravenous feeding). These mothers are also more likely to have negative emotions about their relation with the child (e.g. inability to hug, feed and take care of the child on their own enhances the feeling of separation; experienced helplessness and sense of no control, inability to help the child or spare him/her pain).

The results of the conducted research on a sample of women after premature labor have shown significantly negative correlations between the level of Extraversion, Openness and Agreeableness and the level of stress experienced mostly in the context of parent-child relation and parental competence (Factor III SSR:OITN). Extraversion, Agreeableness and Openness to experience are traits protecting against stress and are related to life optimism, livelihood, and activity. Moreover, they correspond to a different manner of coping with stress, which is more task-oriented and therefore more constructive than the one concentrated on emotions or avoidance. They favor creativity in new situations, along with tolerance and openness in interpersonal relations $[15,16,28-30]$.

It may be assumed that mothers with higher level of Extraversion, Openness to experience, and Agreeableness tend to experience less negative feelings in their relations with the child (sense of guilt, insecurity, grief, alienation, unreality of the situation), as well as with medical staff (concerns, insecurity, envy) and have a higher opinion about their own parental competence. 
The scope of Conscientiousness has shown no significant correlation between the stress level experienced by women in view of prematurity.

Most of the literature reports on maternal functioning during hospitalization of their infants after premature birth concentrated mainly on the results of the experienced trauma. The personality factors significantly influencing the process were taken into consideration to a minor extent. The correlations between personality traits and the level of stress experienced due to prematurity presented in our study substantially explain the differences observed in maternal psychological functioning after premature labor. The knowledge of the above correlations allows to undertake appropriate measures, each time perfectly fitting the patient's individual needs, which remains of the utmost importance in terms of prevention of mental health and psychosomatic disorders due to severe stress. As an example, patients with high level of Neuroticism should receive extensive support in increasing their parental competence by initiating contacts between the mother and the child (including physical contact, which the mothers often resist); encouragement of this contact; engagement of the mother in taking care of the child and in taking partial responsibility for a particular aspect of it, which will increase her sense of confidence in her role of a mother; reinforcing her skills to read the child's signals and to build an emotional connection with the child. Patients with lower level of Extraversion, Openness to experience, and Agreeableness are significantly more prone to experiencing stress with regard to a relationship with the child and sense of parental competence. Taking everything into consideration, the following actions are recommended to be taken:

- ensuring a sense of security and good contact with personnel:

- emotional decompression - getting rid of negative emotions such as the feelings of guilt, uncertainty, grief, sadness;

- making the stressful situation seem real (individuals with lower level of Extraversion have the tendency to experience the feeling of unreality and to alienate themselves from a stressful situation);

- increasing parental competence through analogous actions as in the case of mothers with higher level of Neuroticism.

Such actions lower the level of stress and prevent mothers from experiencing negative emotions, which, if experienced for a long period of time, contribute significantly to psychiatric disorders.

\section{CONCLUSIONS}

The results of the research conducted in this study indicate that there are significant correlations between the level and structure of stress experienced due to prematurity and personality traits. The described relations may explain the differences observed in maternal psychological functioning after premature labor and allow both, appropriate interpretation of patient behavior and implementation of an effective treatment. Our findings suggest a need for conducting new, larger sample-size studies on stress induced by prematurity, investigating other clinical control groups to compare their results with the results of the studied sample and developing new diagnostic methods adjusted to the situation of prematurity.

\section{Conflict of interests}

The authors declare that there is no conflict of interests regarding the publication of this paper.

\section{REFERENCES}

1. Kukreja B, Datta V, Bhakhri BK, Singh P, Khan S. Persistent postnatal depression after preterm delivery. Arch Womens Ment Health. 2012, 15 (1), 73-74.

2. Namaky D, Herzberg J, Dehoop T, Jones E, Wedig K, Marcotte M. Long-term maternal depression after expectant management of early preterm birth. Am J Reprod Med. 2011, 56 (11-12), 479-484.

3. Korja R, Latva R, Lehtonen L. The effects of preterm birth on mother-infant interaction and attachment during the infant's first two years. Acta Obstet Gynecol Scand. 2012, 91 (2), 164-173.

4. Holditch-Davis D, Miles MS, Burchinal MR, Goldman BD. Maternal role attainment with medically fragile infants: Part 2. relationship to the quality of parenting. Res Nurs Health. 2011, 34 (1), 35-48.

5. Holditch-Davis D, BartlettTR, Blickman AL, Miles MS. Posttraumatic stress symptoms in mothers of premature infants. J Obstet Gynecol Neonatal Nurs. 2003, 32 (2), 161-171.

6. Carvalho AE, Linhares MB, Padovani FH, Martinez FE. Anxiety and depression in mothers of preterm infants and psychological intervention during hospitalization in neonatal ICU. Span J Psychol. 2009, 12 (1), 161-170.

7. Morisod-Harari M, Borghini A, Hohlfeld P, Forcada-Guex M, Muller-Nix $C$. Influence of prenatal hospitalization on parental stressful experience in the case of a premature birth. J Gynecol Obstet Biol Reprod (Paris). 2013, 42 (1), 64-70.

8. Miles MS, Holditch-Davis D, Schwartz TA, Scher M. Depressive symptoms in mothers of prematurely born infants. J Dev Behav Pediatr. 2007, 28 (1), 36-44.

9. Veddovi M, Kenny DT, Gibson F, Bowen J, Starte D. The relationship between depressive symptoms following premature birth, mother's coping style and knowledge if infant development. J Reprod Infant Psyc. 2001, 19 (4), 313-323.

10. Madu SN, Roos JJ. Depression among mothers with preterm infants and their stress-coping strategies. Soc Behav Personal. 2006, 34 (7), 877-890.

11. Davis L, Edwards $\mathrm{H}$, Mohay $\mathrm{H}$, Wollin J. The impact of very premature birth on the psychological health of mothers. Early Hum Dev. 2003, 73 (1-2), 61-70.

12. Kersting $A$, Dorsch $M$, Wesselmann $U$ [et al.]. Maternal posttraumatic stress response after the birth of a very low-birth-weight infant. J Psychosom R. 2004, 57 (5), 473-476.

13. Holditch-Davis D, BartlettTR, Blickman AL, Miles MS. Posttraumatic stress symptoms in mothers of premature infants. J Obstet Gynecol Neonatal Nurs. 2003, 32 (2), 161-171.

14. Jotzo M, Poets CF. Helping Parents Cope With the Trauma of Premature Birth: An Evaluation of a Trauma-Preventive Psychological Intervention. Pediatrics. 2005, 115 (4), 915-919.

15. Costa PT, Somerfield MR, McCrae RR. Personality and coping: a reconceptualization. In: Zeidner M, Endler NS. (eds.). Handbook of coping: theory, research, applications. New York: Wiley; 1996, 44-61.

16. Costa PT, McCrae RR. Four ways Five Factors are Basic. Personality and Individual Differences. 1992, 13, 653-665.

17. Jaeschke R, Siwek M, Dudek D. Poporodowe zaburzenia nastroju - update 2012. Neuropsychiatry and Neuropsychology. 2012, 7 (3), 113-121. 
18. Kiepura E, Kmita G, Cieślak-Osik B, Urmańska W, Lewandowska D. Neonatal behavioural assessment of pre-term and full-term infants as experienced by parents. Dev Period Med. 2011, 15 (3 Pt 2), 414-420.

19. Davis L, Mohay H, Edwards H. Mother's involvement in caring for their premature infants: an historical overview. J Adv Nurs. 2002, 42 (6), 578-586.

20. Madu SN, Roos JJ. Depression among mothers with preterm infants and their stress-coping strategies. Soc Behav Personal. 2006, 34 (7), 877-890.

21. Klebanov PK, Brooks-Gunn J, McCormick MC. Maternal Coping Strategies and Emotional Distress: Results of an Early Intervention Program for Low Birth Weight Young Children. Dev Psychol. 2001, 37 (5), 654-667.

22. Davis L, Edwards $H$, Mohay $H$, Wollin J. The impact of very premature birth on the psychological health of mothers. Early Hum Dev. 2003, 73 (1-2), 61-70.

23. Tallandini MA, Morsan V, Macagno F. Preterm birth and Assisted Reproductive Technology/ART: maternal emotional wellbeing and quality of mother-newborn interaction during the first three months of life. Early Hum Dev. 2012, 88 (6), 397-402.
24. Carter M, Miles MS. The Parental Stressor Scale: Pediatric Intensive Care Unit. Matern Child Nurs J. 1989, 18, 187-198.

25. Reid T, Bramwell R. Using the Parental Stressor Scale: NICU with a British sample of mothers of moderate risk preterm infants. J Reprod Infant Psyc. 2003, 21 (4), 279-291.

26. Reid T, Bramwell R, Booth N, Weindling AM. A new stressor scale for parents experiencing neonatal intensive care: the NUPS (Neonatal Unit Parental Stress) scale. J Reprod Infant Psyc. 2007, 25 (1), 66-82.

27. Libera A, Leszczyńska-Gorzelak B, Oleszczuk J. Zastosowania Skali Stresu Rodziców: OITN (SSR:OITN) w diagnostyce klinicznej kobiet po porodzie przedwczesnym. Ginekol Pol. 2013, 84 (4), 281-285.

28. Zawadzki B, Strelau J, Szczepaniak P, Śliwińska M. Inwentarz Osobowości NEO-FFI Costy i McCrae. Podręcznik. Warszawa: Pracownia Testów psychologicznych PTP; 1998.

29. Ogińska-Bulik N, Juczyński Z. Osobowość. Stres a zdrowie. Warszawa: Wydawnictwo Difin; 2008

30. Pervin LA. Psychologia osobowości. Gdańsk: Gdańskie Wydawnictwo Psychologiczne; 2002 